\title{
Puna-apilasäilörehun korjuuajan vaikutus maidon rasvahappokoostumukseen
}

\author{
Aila Vanhatalo ${ }^{1}$, Pirjo Pursiainen ${ }^{1}$ ja Mikko Tuori ${ }^{2}$ \\ ${ }^{1)}$ Kotieläintieteen laitos, PL 28, 00014 Helsingin yliopisto, etunimi.sukunimi@ helsinki.fi, \\ ${ }^{2)}$ MTT, Kotieläintuotannon tutkimus, Tervamäentie 179, 05840 Hyvinkää, etunimi.sukunimi@mtt.fi
}

\section{Tiivistelmä}

Tutkimuksessa selvitettiin puna-apilasäilörehun korjuuajankohdan vaikutusta maidon rasvahappokoostumukseen. Apilarehujen syöntiä, sulavuutta ja maidontuotantovaikutusta koskevat tutkimustulokset on esitetty aikaisemmin (Pursiainen ym. 2006). Koerehut tehtiin puhtaasta punaapilanurmesta ensikasvun aikaisesta (AA) ja myöhäisestä (AM) kehitysvaiheesta sekä näiden jälkikasvuista (AAJ ja AMJ, vastaavasti). Kontrollina oli timotei-nurminatakasvustosta aikaisessa (TNA) ja myöhäisessä (TNM) kehitysvaiheessa tehty säilörehu. Rehut oli säilötty pyöröpaaleihin muurahaishappopohjaista säilöntäainetta käyttäen. Tutkimus tehtiin 12 Ay-lehmällä change over kokeena, jossa oli neljä kolmen viikon mittaista jaksoa. Lehmät jaettiin tuotoksen mukaan kahteen blokkiin (2-3 kertaa poikineet ja ensikot) ja ne saivat säilörehua vapaasti. Vilja-rypsipohjaista väkirehua annettiin 10.5 (useasti poikineet) tai $8.4 \mathrm{~kg} / \mathrm{pv}$ (ensikot).

Koekäsittelyiden välillä ei ollut eroja energiakorjatussa maitotuotoksessa tai maidon rasvapitoisuudessa. Apilasäilörehuruokinta vaikutti kuitenkin selvästi maidon rasvahappokoostumukseen. Se lisäsi kerta- ja monityydyttymättömien rasvahappojen ja vähensi palmitiinihapon (C16:0) osuutta maitorasvassa heinäkasviruokintoihin verrattuna. Apilaruokinta lisäsi erityisesti $\alpha-$ linoleenihapon (18:3 n-3) osuutta maitorasvassa (0.87 (AA), 0.67 (AM), 0.92 (AAJ), 0.93 (AMJ), 0.44 (TNA) ja $0.48 \%$ (TNM)) vaikutuksen ollessa suurempi lehmien syödessä apilan jälkikasvu- kuin ensikasvurehuja. Sen osuus maitorasvassa oli myös suurempi lehmien syödessä apilan ensikasvusta aikaisin korjattuja säilörehuja myöhään korjattuihin rehuihin verrattuna. Tulokset vahvistavat tutkimusprojektin aikaisemmassa kokeessa saatuja tuloksia puna-apilan edullisesta vaikutuksesta maidon rasvahappokoostumukseen.

Asiasanat: puna-apilasäilörehu, lypsylehmä, maidon rasvahappokoostumus

\section{Johdanto}

Maidon sisältämä rasva on pääosin tyydyttynyttä rasvaa, jota pidetään terveydelle haitallisena. Maidon rasvahappokoostumusta voidaan kuitenkin muuttaa terveyden kannalta suotuisammaksi lehmien ruokinnan avulla. Yleensä tyydyttymättömien rasvahappojen osuutta maitorasvassa on pyritty lisäämään sisällyttämällä lehmien väkirehuannokseen kasviöljyjä. Runsaat rasvalisäykset ruokinnassa voivat kuitenkin vaikuttaa haitallisesti karkearehun syöntiin ja rehuannoksen kuidun sulatukseen.

Viimeaikaiset tutkimustulokset ovat osoittaneet, että maidon rasvahappokoostumukseen voidaan vaikuttaa myös runsaaseen karkearehun käyttöön perustuvan ruokinnan avulla. Maidon monityydyttymättömien rasvahappojen (PUFA), erityisesti $\alpha$-linoleenihapon $(\mathrm{C} 18: 3 \mathrm{n}-3)$, osuus jopa kaksin- tai kolminkertaistui maitorasvassa lähinnä palmitiinihapon kustannuksella, kun punaapilasäilörehu korvasi heinäkasvisäilörehun lehmien ruokinnassa (Dewhurst ym. 2003, Tuori ym. 2004, Vanhatalo ym. 2007). Suurin muutos maidon rasvahappokoostumuksessa saatiin ruokittaessa aikaisin korjattua puna-apilasäilörehua (Vanhatalo ym. 2007).

Tämän tutkimuksen tarkoituksena oli selvittää puna-apilasäilörehun korjuuajankohdan (kasvuaste, sato) vaikutusta maidon rasvahappokoostumukseen. Apilarehujen syöntiä, sulavuutta ja maidontuotantovaikutusta koskevat tulokset kokeesta on esitetty aikaisemmin (Pursiainen ym. 2006). Tutkimus kuului MMM:n rahoittaman Luomututkimusohjelman projektiin "Puna-apila tehokkaasti luomumaidoksi", johon saatiin myös Huoltovarmuuskeskuksen rahoitustukea.

\section{Aineisto ja menetelmät}

Tutkimuksen koejärjestelyt on selostettu yksityiskohtaisesti aikaisemmin (Pursiainen ym. 2006), joten ne selostetaan tässä vain lyhyesti pääkohdittain. 
Apilarehut tehtiin kesällä 2004 Viikin opetus- ja tutkimustilan puna-apilakasvustosta (lajike Varte), jota ei lannoitettu. Apilarehut säilöttiin ensikasvun aikaisesta (AA) ja myöhäisestä (AM) kehitysvaiheesta sekä näiden jälkikasvuista (AAJ ja AMJ, vastaavasti) (taulukko 1). Kontrollirehuiksi säilöttiin ensisadon timotei-nurminatakasvustoa sekä aikaisessa (TNA) että myöhäisessä kehitysvaiheessa (TNM). Kaikki rehut säilöttiin pyöröpaaleihin muurahaishappopohjaista AIV2Plussäilöntäainetta $(5$ 1/tn) käyttäen.

Tutkimus tehtiin Viikin opetus- ja tutkimustilan navetassa 12 ay-lehmällä cyclic change overkokeena, jossa oli neljä kolmen viikon mittaista jaksoa. Lehmät jaettiin tuotoksen mukaan kahteen blokkiin (kaksi kertaa poikineet ja ensikot), ja ne saivat vapaasti säilörehua, jota jaettiin kolme kertaa päivässä. Väkirehuna oli ohran ja kauran (50:50) sekä rypsipuristeen (23.8 \% väkirehun määrästä) seos, jota annettiin 10,5 (blokki 1) tai $8,4 \mathrm{~kg} / \mathrm{pv}$ (blokki 2). Väkirehu jaettiin kuudessa yhtä suuressa erässä. Rehut ja rehujätteet punnittiin päivittäin. Maitotuotos mitattiin päivittäin (Tru-Test FV). Kunkin jakson viimeisellä viikolla maidosta otettiin näyte neljältä peräkkäiseltä lypsykerralta. Yhdistetystä näytteestä määritettiin Valion Lapinlahden aluelaboratoriossa rasva-, valkuais-, laktoosija ureapitoisuus sekä Kotieläintieteen laitoksen laboratoriossa pakastetusta näytteestä maitorasvan rasvahappokoostumus kaasukromatografisesti kuten Tuorin ym. (2004) kokeessa.

Keruukauden aikana säilö- ja väkirehuista kerättiin päivittäin näytettä rehunpunnitusten yhteydessä analyyseja varten. Syönti- ja tuotostiedot laskettiin jokaisen jakson viimeiseltä viikolta. Tulokset testattiin SASin Mixed proseduurilla. Tilastollisessa mallissa oli mukana ruokinta, blokki, jakso sekä blokki*jakso yhdysvaikutus. Eläin oli blokin sisällä satunnaistekijänä. Ruokinnan vaikutusta tutkittiin edelleen jakamalla se kontrasteihin: 1) apilan ensi- vs. jälkikasvu, 2) apilan kehitysvaihe, 3) apilan ensi- ja jälkikasvu*kehitysvaihe -yhdysvaikutus, 4) kasvilaji sekä 5) kasvilaji*kehitysvaihe -yhdysvaikutus. Kokeesta poistettiin yhden lehmän havainnot muista täysin poikkeavan lypsykäyrän vuoksi.

\section{Tulokset ja tulosten tarkastelu}

Puna-apilasäilörehujen korjuuajankohdat, kehitysvaihe ja kemiallinen koostumus sekä säilöntälaatu on esitetty taulukossa 1 (Pursiainen ym. 2006). Puna-apilarehut jouduttiin paalaamaan hankalissa sääolosuhteissa, joten säilörehujen kuiva-ainepitoisuudet jäivät melko mataliksi ja säilörehut olivat myös melko pitkälle käyneitä sisältäen niukasti sokeria ja runsaasti käymishappoja (Pursiainen ym. 2006).

Taulukko 1. Säilörehujen kemiallinen koostumus ja säilöntälaatu.

\begin{tabular}{|c|c|c|c|c|c|c|}
\hline Säilörehu & AA & AM & AAJ & AMJ & TNA & TNM \\
\hline Niittopäivämäärä & 1.7.2004 & 14.7.2004 & 24.8 .2004 & 24.8.2004 & 15.6.2004 & 30.6 .2004 \\
\hline Kehitysvaihe & $\begin{array}{l}\text { Kukinta } \\
\text { alussa }\end{array}$ & $\begin{array}{c}\text { Kukinta } \\
\text { loppu- } \\
\text { vaiheessa }\end{array}$ & $\begin{array}{l}\text { Täydessä } \\
\text { kukassa }\end{array}$ & $\begin{array}{c}\text { Kukinta } \\
\text { alussa }\end{array}$ & & \\
\hline Kuiva-aine, g/kg & 180 & 224 & 251 & 219 & 321 & 277 \\
\hline $\mathrm{pH}$ & 4,05 & 4,30 & 4,22 & 4,31 & 4,25 & 4,11 \\
\hline \multicolumn{7}{|l|}{ g/kg KA } \\
\hline Tuhka & 87 & 97 & 90 & 102 & 63 & 54 \\
\hline Raakavalkuainen & 166 & 165 & 170 & 193 & 112 & 90 \\
\hline NDF-kuitu & 395 & 391 & 373 & 348 & 541 & 601 \\
\hline iNDF & 184 & 204 & 177 & 141 & 82 & 162 \\
\hline Maitohappo & 102 & 106 & 86 & 98 & 42 & 44 \\
\hline Etikkahappo & 27 & 31 & 20 & 29 & 9 & 9 \\
\hline Propionihappo & 0,24 & 0,62 & 0,18 & 0,36 & 0,11 & 0,15 \\
\hline Voihappo & 0,06 & 0,49 & 0,05 & 0,05 & 0,12 & 0,08 \\
\hline Vesiliuk. hiilihydr. & 3 & 12 & 33 & 8 & 102 & 45 \\
\hline Etanoli & 40 & 34 & 37 & 29 & 45 & 75 \\
\hline Liuk.N, g/kg N & 360 & 470 & 372 & 389 & 639 & 625 \\
\hline $\mathrm{NH}_{3}-\mathrm{N}, \mathrm{g} / \mathrm{kg} . \mathrm{N}$ & 62 & 112 & 68 & 66 & 53 & 90 \\
\hline D-arvo, g/kg KA & 639 & 591 & 619 & 651 & 696 & 619 \\
\hline
\end{tabular}


Koekäsittelyiden välillä ei ollut merkitseviä eroja energiakorjatussa maitotuotoksessa tai maidon rasvapitoisuudessa (Pursiainen ym. 2006). Apilasäilörehuruokinta vaikutti kuitenkin selvästi maidon rasvahappokoostumukseen (taulukko 2). Kuten Dewhurst'in ym. (2003) ja Vanhatalon ym. (2007) kokeissa, myös tässä kokeessa apilaruokinta lisäsi $(\mathrm{P}<0.001)$ PUFA:n ja vähensi $(\mathrm{P} \leq 0.01)$ erityisesti palmitiinihapon C16:0 mutta myös muiden keskipitkäketjuisten rasvahappojen (C10:0-C14:0) osuutta maitorasvassa heinäkasviruokintoihin verrattuna. Samoin kuin Tuorin ym. (2004) kokeessa punaapilarehua saaneiden lehmien maidon $\alpha$-linoleenihapon pitoisuus maitorasvassa kaksinkertaistui heinä-

Taulukko 2. Apilasäilörehun kasvuasteen vaikutus maidon rasvahappokoostumukseen (g/100 g rasvahappoja).

\begin{tabular}{|c|c|c|c|c|c|c|c|c|c|c|c|c|}
\hline & \multirow{2}{*}{$\begin{array}{c}\text { AA } \\
(n=7)\end{array}$} & \multirow{2}{*}{$\begin{array}{c}\text { AM } \\
(n=7)\end{array}$} & \multirow{2}{*}{$\begin{array}{l}\text { AAJ } \\
(n=8)\end{array}$} & \multirow{2}{*}{$\begin{array}{l}\text { AMJ } \\
(n=7)\end{array}$} & \multirow{2}{*}{$\begin{array}{l}\text { TNA } \\
(n=8)\end{array}$} & \multirow{2}{*}{$\begin{array}{l}\text { TNM } \\
(n=7)\end{array}$} & \multirow[b]{2}{*}{ SEM } & \multicolumn{5}{|c|}{ Tilastollinen merkitsevyys } \\
\hline & & & & & & & & 1 & 2 & 3 & 4 & 5 \\
\hline $\mathrm{C} 4: 0$ & 4,36 & 4,17 & 4,19 & 4,24 & 4,07 & 4,19 & 0,087 & NS & $*$ & NS & $*$ & $*$ \\
\hline C6:0 & 2,48 & 2,42 & 2,51 & 2,48 & 2,48 & 2,46 & 0,036 & o & NS & o & NS & NS \\
\hline $\mathrm{C} 8: 0$ & 1,44 & 1,40 & 1,51 & 1,45 & 1,50 & 1,44 & 0,030 & $* *$ & NS & $*$ & $*$ & NS \\
\hline C10:0 & 3,03 & 3,03 & 3,29 & 3,15 & 3,39 & 3,10 & 0,098 & $* *$ & NS & NS & $* * *$ & $*$ \\
\hline C12:0 & 3,33 & 3,33 & 3,68 & 3,49 & 3,90 & 3,41 & 0,115 & $* * *$ & NS & NS & $* * *$ & $* *$ \\
\hline C14:0 & 10,95 & 11,17 & 11,53 & 11,38 & 12,20 & 11,39 & 0,190 & $*$ & NS & NS & $* * *$ & $* *$ \\
\hline C14:1 & 0,94 & 1,01 & 1,04 & 0,98 & 1,11 & 1,09 & 0,039 & NS & $*$ & NS & $* * *$ & NS \\
\hline C15:0 & 0,83 & 1,06 & 1,07 & 1,01 & 1,02 & 0,96 & 0,062 & NS & $*$ & NS & NS & $*$ \\
\hline isoC15:0 & 0,16 & 0,15 & 0,15 & 0,15 & 0,20 & 0,19 & 0,007 & NS & NS & NS & $* * *$ & NS \\
\hline anteisoC15:0 & 0,35 & 0,33 & 0,34 & 0,33 & 0,38 & 0,37 & 0,015 & NS & NS & NS & $*$ & NS \\
\hline C16:0 & 27,21 & 27,82 & 27,75 & 27,74 & 29,95 & 27,92 & 0,513 & NS & NS & NS & $* *$ & $* *$ \\
\hline isoC16:0 & 0,17 & 0,18 & 0,17 & 0,17 & 0,18 & 0,18 & 0,009 & NS & NS & NS & NS & NS \\
\hline C16:1 & 1,04 & 1,16 & 1,06 & 1,04 & 1,09 & 1,16 & 0,050 & o & $*$ & o & NS & NS \\
\hline C17:0 & 0,46 & 0,47 & 0,47 & 0,45 & 0,38 & 0,41 & 0,010 & NS & NS & NS & $* * *$ & NS \\
\hline isoC17:0 & 0,19 & 0,19 & 0,17 & 0,17 & 0,23 & 0,22 & 0,007 & $*$ & NS & NS & $* * *$ & NS \\
\hline C18:0 & 11,71 & 11,30 & 11,33 & 11,58 & 11,38 & 11,54 & 0,278 & NS & NS & NS & NS & NS \\
\hline C18:1t6-8 & 0,29 & 0,27 & 0,26 & 0,26 & 0,19 & 0,22 & 0,012 & o & NS & $\mathrm{NS}$ & $* * *$ & $*$ \\
\hline C18:1t9 & 0,24 & 0,25 & 0,24 & 0,24 & 0,19 & 0,22 & 0,012 & NS & NS & NS & $* *$ & NS \\
\hline $\mathrm{C} 18: 1 t 10$ & 0,27 & 0,26 & 0,26 & 0,26 & 0,18 & 0,21 & 0,013 & NS & NS & NS & $* * *$ & NS \\
\hline C18:1t11 & 1,22 & 1,14 & 1,10 & 1,13 & 0,95 & 1,02 & 0,050 & o & NS & NS & $* * *$ & $*$ \\
\hline C18:1t12 & 0,27 & 0,25 & 0,22 & 0,24 & 0,16 & 0,18 & 0,015 & $*$ & $*$ & NS & $* * *$ & o \\
\hline C18:1t13-14 & 0,56 & 0,52 & 0,51 & 0,57 & 0,43 & 0,39 & 0.029 & NS & $*$ & NS & $* * *$ & NS \\
\hline C18:1t15 & 0,27 & 0,34 & 0,42 & 0,44 & 0,33 & 0,31 & 0,065 & $\mathrm{o}$ & NS & NS & NS & NS \\
\hline $\mathrm{C} 18: 1 c 9$ & 21,57 & 21,56 & 19,98 & 20,53 & 18,81 & 21,71 & 0,545 & $*$ & NS & NS & $*$ & $* *$ \\
\hline C18:1c11 & 0,50 & 0,52 & 0,42 & 0,41 & 0,38 & 0,50 & 0,032 & $* *$ & NS & NS & $*$ & o \\
\hline C18:2 (n-6) & 2,36 & 2,23 & 2,43 & 2,34 & 1,89 & 2,08 & 0,075 & $*$ & NS & $* *$ & $* * *$ & $* * *$ \\
\hline C18:3 (n-3) & 0,87 & 0,67 & 0,92 & 0,93 & 0,44 & 0,48 & 0,048 & $* * *$ & $* *$ & $*$ & $* * *$ & $* *$ \\
\hline CLA $c 9 t 11$ & 0,60 & 0,58 & 0,54 & 0,57 & 0,45 & 0,53 & 0,023 & $*$ & NS & $\mathrm{NS}$ & $* * *$ & $* *$ \\
\hline C20:0 & 0,47 & 0,18 & 0,24 & 0,19 & 0,19 & 0,19 & 0,112 & NS & NS & NS & NS & NS \\
\hline C4-C14 & 26,53 & 26,53 & 27,75 & 27,17 & 28,65 & 27,07 & 0,387 & $* *$ & NS & NS & $* * *$ & $* *$ \\
\hline C18: $1 t$ yht. $^{1}$ & 3,12 & 3,00 & 3,00 & 3,15 & 2,44 & 2,58 & 0,119 & NS & NS & NS & $* * *$ & NS \\
\hline PUFA & 3,83 & 3,48 & 3,89 & 3,84 & 2,78 & 3,09 & 0,113 & $* *$ & $*$ & $* *$ & $* * *$ & $* * *$ \\
\hline MUFA & 27,19 & 27,27 & 25,48 & 26,11 & 23,83 & 27,02 & 0,592 & $*$ & NS & NS & $* *$ & $* *$ \\
\hline Tyydyttymättömät & 31,00 & 30,82 & 29,37 & 29,96 & 26,63 & 30,01 & 0,586 & $*$ & NS & NS & $* * *$ & $* *$ \\
\hline Tyydyttyneet & 67,24 & 67,26 & 68,48 & 67,77 & 71,29 & 68,03 & 0,630 & NS & NS & NS & $* * *$ & $*$ \\
\hline
\end{tabular}

AA=apilan ensikasvu, aikainen kehitysvaihe; AM=apilan ensikasvu, myöhäinen kehitysvaihe; AAJ= AA:n jälkikasvu; AMJ =AM:n jälkikasvu; TNA=timotei-nurminata, aikainen kehitysvaihe; TNM=timotei-nurminata, myöhäinen kehitysvaihe.

PUFA=monityydyttymättömät rasvahapot, MUFA=kertatyydyttymättömät rasvahapot.

Tilastollinen merkitsevyys $* * *=p<0.001, * *=\mathrm{p}<0.01, *=\mathrm{p}<0.05, \mathrm{o}=\mathrm{p}<0.10$.

Kontrastit: $1=$ Apilan ensikasvu vs. jälkikasvu, $2=$ Apila aikaisin vs. myöhään korjattu, $3=1 * 2$ yhdysvaikutus, 4=apila vs. heinäkasvinurmi, $5=$ kasvilaji*kehitysvaihe

${ }^{1} \mathrm{C} 18: 1$ trans monoeenit=trans6-8+trans9+trans 10+trans11+trans13-14+trans 15. 
kasviruokintoihin verrattuna. Dewhurstin ym. (2003) ja Vanhatalon ym. (2007) tutkimuksissa punaapilaa saaneiden lehmien maidon $\alpha$-linoleenihapon pitoisuus maitorasvassa oli jopa kolminkertainen heinäkasviruokintoihin verrattuna.

Tutkimusten väliset erot maidon $\alpha$-linoleenihappopitoisuuksissa saattavat liittyä eroihin kokeissa käytettyjen puna-apilasäilörehujen kasvuasteissa. Vanhatalon ym. kokeessa (2007) $\alpha$ linoleenihapon pitoisuus maitorasvassa (1,34 vs. $0,88 \%)$ oli selvästi suurempi aikaisesta ensikas vusta kuin myöhäisestä ensikasvusta korjattua puna-apilarehua syötettäessä. Myös tässä kokeessa $\alpha$ linoleenihapon pitoisuus maitorasvassa oli suurempi syötettäessä ensikasvun aikaisin kuin myöhään korjattua apilasäilörehua ( 0,87 vs. $0,67 \%)$. Tässä kokeessa ensikasvusta tehtyjen apilarehujen D-arvot olivat kuitenkin pienempiä kuin aikaisemmin tehdyssä kokeessa (Vanhatalo ym. 2007), joten tämän kokeen apilarehut oli korjattu todennäköisesti myöhäisemmässä kasvuvaiheessa. Punaapilasäilörehulla tuotetun maidon $\alpha$-linoleenihappopitoisuuksissa saattaa esiintyä vaihtelua myös siitä syystä, että rehuannoksen karkearehu:väkirehu -suhde on vaihdellut jossain määrin eri kokeissa. Pienempi $\alpha$-linoleenihapon pitoisuus tässä kokeessa saattaa osaksi johtua myös siitä, että karkearehun osuus rehuannoksesta oli tässä kokeessa pienempi kuin Vanhatalon ym. (2007) kokeessa. Tämän kokeen rehut olivat pitkälle käyneitä siilossa, joten lehmät eivät syöneet niitä yhtä runsaasti kuin aikaisemmin tehdyn kokeen rajoittuneesti käyneitä rehuja.

Tässä tutkimuksessa verrattiin puna-apilasäilörehunurmen ensikasvun kasvuasteen lisäksi myös puna-apilan ensimmäisen ja toisen sadon vaikutusta maidon rasvahappokoostumukseen. Maidon $\alpha$-linoleenihapon ja PUFA:n osuus maitorasvassa oli jonkin verran suurempi $(\mathrm{P} \leq 0.01)$, mutta kertatyydyytymättömien rasvahappojen (MUFA) osuus pienempi $(\mathrm{P}<0.05)$ syötettäessä apilan toisen sadon rehuja kuin ensimmäisen sadon rehuja. Palmitiinihapon pitoisuuksissa ei ollut satojen välisiä eroja, mutta C10:0-C14:0 -rasvahappojen pitoisuudet olivat hiukan suurempia $(\mathrm{P} \leq 0.05)$ syötettäessä 2 . sadon kuin 1. sadon apilarehuja. Apilan 1. ja 2. sadon väliset erot maidon rasvahappokoostumuksessa johtuvat luultavasti eroista 1 . ja 2. sadon rehujen kasvuasteessa. Toisen sadon rehut sisälsivät vähemmän kuitua ja sulamatonta kuitua kuin 1. sadon rehut. Lisäksi niiden säilöntälaatu oli jonkin verran parempi kuin 1. sadon rehujen ja lehmät söivät niitä keskimäärin enemmän kuin 1. sadon rehuja (12,3 vs. 9,9 kg ka/pv; Pursiainen ym. 2006).

Tässä kokeessa. ei määritetty säilörehujen rasvahappopitoisuuksia, joten ei ole mahdollista arvioida oliko koekäsittelyiden välillä eroja rasvahappojen saannissa. Aikaisemmassa kokeessa (Vanhatalo ym. 2007) apila- ja heinäkasvisäilörehujen rasvahappojen pitoisuuksissa ei ollut oleellisia eroja, joten ruokintojen välillä todetut erot maidon rasvahappokoostumuksissa saattavat liittyä pötsin rasvametaboliaan. Onkin esitetty, että puna-apilan edullinen vaikutus maitorasvan koostumukseen saattaisi johtua siitä, että puna-apila vähentää rasvahappojen biohydrogenaatiota pötsissä heinäkasviin verrattuna (Dewhurst ym. 2006). Puna-apilan luontaisesti sisältämä polyfenolioksidaasi-entsyymi (Jones ym. 1995) mahdollisesti hillitsee biohydrogenaatiota edeltävää rasvahappojen lipolyysiä ja siten vähentää pötsin biohydrogenaatiota. Tästä aiheesta tarvitaan kuitenkin lisätutkimuksia. Samoin pitäisi selvittää voidaanko puna-apilasäilörehun korjuu- tai säilöntämenetelmillä vaikuttaa punaapilarehun rasvahappopitoisuuteen ja -koostumukseen.

Tässä ja edellä mainituissa muissa puna-apilakokeissa, joissa on määritetty maidon rasvahappokoostumus, väkirehulisänä on ollut eri valkuaisrouheiden seosta (Dewhurst ym. 2003) tai rypsipuristetta (Vanhatalo ym. 2007) sisältävä viljapohjainen väkirehu. Pitäisi myös selvittää voidaanko maidon rasvahappokoostumusta muuttaa edelleen terveydelle suotuisammaksi täydentämällä puna-apilapohjaista ruokintaa erilaisilla kasviöljyillä.

\section{Johtopäätökset}

Koekäsittelyiden välillä ei ollut eroja energiakorjatussa maitotuotoksessa tai maidon rasvapitoisuudessa, mutta apilasäilörehuruokinta vaikutti selvästi maidon rasvahappokoostumukseen. Se lisäsi lisäsi kerta- ja monityydyttymättömien rasvahappojen ja vähensi palmitiinihapon osuutta maitorasvassa heinäkasviruokintoihin verrattuna. Apilaruokinta lisäsi erityisesti $\alpha$-linoleenihapon osuutta maitorasvassa vaikutuksen ollessa suurempi lehmien syödessä apilan jälkikasvu- kuin ensikasvurehuja. Sen osuus maitorasvassa oli myös suurempi lehmien syödessä apilan ensikasvusta aikaisin korjattuja säilörehuja myöhään korjattuihin rehuihin verrattuna. Tulokset vahvistavat tutkimusprojektin aikaisemmassa kokeessa saatuja tuloksia puna-apilan edullisesta vaikutuksesta maidon rasvahappokoostumukseen. 


\section{Kirjallisuus}

Dewhurst, R.J., Fisher, W.J., Tweed, J.K.S. \& Wilkins, R.J. 2003. Comparison of legume silages for milk production. 1. Production responses with different levels of concentrate. Journal of Dairy Science 86:2598-2611. Dewhurst, R.J. Shingfield, K.J., Lee, M.R.F. Scollan. N.D. 2006. Increasing the concentrations of beneficial poly-unsaturated fatty acids in milk produced by dairy cows in high forage systems. Anim Feed Sci Techn 131, 168-206.

Jones, B.A., Muck, R.E. \& Hatfield R.D. 1995. Red clover extract inhibits legume proteolysis. Journal of Science of Food and Agriculture 67: 329-333.

Pursiainen, P., Tuori, M., Kuoppala, K., Rinne, M., Huhtanen, P. \& Vanhatalo, A. 2006. Punaapilasäilörehun korjuuajan vaikutus maidontuotantoon. Julkaisussa: Maataloustieteen Päivät 2006 [verkkojulkaisu]. Suomen Maataloustieteellisen Seuran julkaisuja no 21. Toim. Anneli Hopponen. Julkaistu 9.1.2006. Saatavilla Internetissä:http://www.smts.fi (Puna-apilasäilörehun korjuuajan vaikutus maidontuotantoon). ISBN 951-9041-49-4.

Tuori, M., Griinari, M. \& Luukkainen, L. 2004. Puna-apila-, vuohenherne- ja nurmisäilörehujen vaikutus maidon linoleenihappopitoisuuteen lypsylehmän ruokinnassa. Julkaisussa: Maataloustieteen Päivät 2004 [verkkojulkaisu]. Suomen Maataloustieteellisen Seuran julkaisuja no 19. Toim. Anneli Hopponen ja Marketta Rinne. Julkaistu 5.1.2004. Saatavilla Internetissä: http://www.agronet.fi/maataloustieteellinenseura/ (Puna-apila-, vuohenherne- ja nurmisäilörehujen vaikutus maidon linoleenihappopitoisuuteen lypsylehmän ruokinnassa ). ISBN 951-9041-47-8.

Vanhatalo, A., Kuoppala, K., Toivonen, V. \& Shingfield, K. 2007. Effects of forage species and stage of maturity on bovine milk fatty acid composition. European Journal of Lipid Science and Technology 109, 856867. 